\title{
O PRINCÍPIO DA VEDAÇÃO DO RETROCESSO E O DIREITO FUNDAMENTAL AO AMBIENTE ECOLOGICAMENTE EQUILIBRADO
}

The principle of the seal and the fundamental right to kick ecologically balanced environment

\section{Caroline Busetti}

\author{
Mestranda do Programa de Pós-graduação em Direito Ambiental e Novos Direitos \\ da Universidade de Caxias do Sul/RS (UCS). Pesquisadora da CAPES. Especia- \\ lista em Direito Público pela Universidade de Brasília/DF. (UnB). Advogada da \\ União no Rio Grande do Sul. E-mail: cbusetti@terra.com.br
}

RECEBIDO EM: 05.09.12

AProvado EM: 17.12 .12

\section{RESUMO}

O direito fundamental ao ambiente ecologicamente equilibrado consiste num direito fundamental completo decorrendo dessa consideração a emanação de um complexo feixe de posições jurídicas jusfundamentais que importam aos indivíduos poderem opor ao Estado direitos de defesa e direitos a prestações fáticas e normativas. O princípio da vedação do retrocesso ambiental encontra fundamento jurídico-constitucional no direito ao ambiente enquanto direito fundamental completo devido à dupla face de imposições que se dirigem ao Estado. Incumbe ao Estado abster-se de práticas legais, administrativas e judiciais que impliquem em decréscimo do patrimônio jusfundamental adquirido pela humanidade, bem como deve orientar suas ações para conferir progressividade às garantias já consolidadas. A vedação do retrocesso se volta a assegurar o núcleo essencial do direito fundamental ao ambiente ecologicamente equilibrado com esteio nos princípios da segurança jurídica, do direito adquirido, do ato jurídico perfeito, da coisa julgada, bem como, nos limites materiais à reforma constitucional. O princípio da vedação do retrocesso ambiental se dirige ao Estado enquanto devedor de abstenções e prestações com 
efeitos gerais sobre todo sistema jurídico devendo a coletividade cooperar para a concretização da proteção ao direito fundamental ao ambiente.

Palavras-chave: Direito fundamental ao ambiente ecologicamente equilibrado. Direito fundamental completo. Princípio da Vedação do RETROCESSO AMBIENTAL.

\section{Abstract}

The fundamental law to the ecologically balanced environment consists of a complete fundamental law accruing from this consideration the emanation of a complex bundle of unsubstantiated juridical positions which matter to the individuals being able to oppose the State defense rights and rights to phatic and normative renders. The principle of environmental regression sealing finds juridical-constitutional ground on the environmental law while being the complete fundamental law due to the double aspect impositions which are directed to the State. It is delegated to the State abstaining itself from legal, administrative and judicial practices which might imply in a decrease of the unsubstantiated patrimony acquired by mankind, such as it must orientate its actions to grant progressivity to the already consolidated guarantees. The regression sealing is aimed to assure the essential nucleus to the environmental fundamental law ecologically balanced with a pillar on the law safety principles, on the acquired law, on the perfect juridical act, on the judged matter, such as, on the material limits to the constitutional reform. The principle of environmental regression sealing is aimed to the State as a debtor of abstentions and renders with general effects over all the juridical system and having the cooperation from the collectivity in order to fulfill the protection to the environmental fundamental law.

Keywords: Fundamental LAW TO THE ECOlOGiCAlly BALANCED environment. Complete fundamental law. Principle of environmental REGRESSION SEALING.

SuMÁrio: Introdução. 1. O direito fundamental ao ambiente ecologicamente equilibrado. 2. O princípio da vedação do retrocesso ambiental: compreensão a partir da perspectiva do direito ao ambiente como um direito fundamental completo. 3. O princípio da vedação do retrocesso ambiental enquanto princípio constitucional implícito. Conclusão. Referências. 


\section{INTRODUÇÃO}

A proliferação de medidas legislativas de corte infraconstitucional tendo por matéria o direito ambiental expõe à evidência a importância da significação dos princípios constitucionais ambientais enquanto normas com eficácia imediata e irrestrita e que possuem a função primordial de informar o sistema jurídico.

A racionalidade do atual constitucionalismo considera que os princípios expressam os valores adotados pela comunidade constitucional e agregam a tarefa primordial de conferir unidade e harmonia a todo ordenamento, atenuando suas dissidências e servindo de fio condutor ao intérprete.

Nesse contexto, perscrutar do reconhecimento da legitimidade de um princípio constitucional voltado ao controle da inexorável atuação do Estado na regulação das relações sociais, sobretudo capaz de impor limites ao exercício da competência legislativa em matéria ambiental, é a tarefa principal da presente investigação. Para tanto, o presente estudo adotará o método hipotético-dedutivo e a técnica de pesquisa bibliográfica e documental e se estruturará em três partes.

$\mathrm{Na}$ primeira parte, a presente investigação se propõe a resgatar a característica de jusfundamentalidade do direito ao meio ambiente ecologicamente equilibrado e apontar para os primeiros indícios situados na Constituição Federal brasileira sobre a existência de limites constitucionais para a atuação do legislador constituinte derivado e para o legislador ordinário em matéria ambiental.

Num segundo momento, este trabalho parte da compreensão de que o meio ambiente consiste em um direito fundamental completo, se voltando a verificar de que modo os complexos feixes de relações jurídicas que lhe são inerentes implicam em interpretar-se pela existência de uma normatividade constitucional defensiva e, ao mesmo tempo, prestacional, apta a defender as prerrogativas desse mesmo direito.

$\mathrm{Na}$ terceira parte do trabalho, serão expostos os argumentos que defendem a legitimidade de um princípio constitucional implícito de vedação do retrocesso ambiental e, a partir de tais premissas, se fará a análise das possibilidades de vinculação normativa do princípio relativas ao Estado e à coletividade, bem como da efetividade jurídico-constitucional para a proteção do direito fundamental ao meio ambiente ecologicamente equilibrado.

\section{O DiReito FUndamental AO AMBIENTE ECOLOGICAMENTE EQUILIBRAdo}

O direito ao meio ambiente ecologicamente equilibrado é compreendido enquanto direito fundamental por resguardar conteúdos vinculados ao princípio da dignidade da pessoa humana e aos princípios da igualdade e da liberdade. 
$\mathrm{O}$ respaldo de jusfundamentalidade do direito ao meio ambiente encontra-se na cláusula de abertura prevista no parágrafo $2^{\circ}$ do art. $5^{\circ}$ da Constituição, a qual defere oportunidade para a legitimação de outros direitos não expressos na Constituição Federal, masquedecorram dos princípios porelaadotados ou dos tratados internacionais em que o Brasil seja parte. $\mathrm{O}$ fato de o direito ao ambiente possuir localização tópica no título VIII da Constituição Federal Brasileira - o qual trata dos direitos sociais portanto, deslocado do Título II - que aborda os direitos e garantias fundamentais - poderia trazer a debate o questionamento sobre sua jusfundamentalidade, contudo, a cláusula de abertura prevista no parágrafo $2^{\circ}$ do art. $5^{\circ}$, que admite a recepção de princípios constitucionais não abarcados pela Constituição, enseja, com maior razão, que o princípio do meio ambiente expresso na Carta Constitucional seja considerado um direito fundamental por guardar consonância com os valores adotados pela comunidade brasileira e refletidos na Constituição.

As normas de direitos fundamentais não são meramente os enunciados das disposições de direitos fundamentais contidas no catálogo da Constituição ${ }^{410}$. A jusfundamentalidade do direito ao ambiente é adquirida a partir de uma leitura material do seu conteúdo e das relações que mantém com os demais valores constitucionais $^{411}$ que informam o sistema jurídico como um todo. Assim, considerada a importância do direito ao meio ambiente na conjuntura dos demais direitos fundamentais como a vida, a integridade física, o desenvolvimento da personalidade e a saúde, valores estes conectados com o princípio da dignidade humana, resta evidente a sua fundamentalidade ${ }^{412}$.

Sobretudo, no plano internacional, o direito ao meio ambiente como direito fundamental está respaldado pelas declarações emitidas no Pacto Internacional de Direitos Econômicos, Sociais e Culturais (1966), na Declaração da Conferência das Nações Unidas sobre Meio Ambiente Humano (Estocolmo, 1972), no Protocolo de San Salvador adicional à Convenção Americana sobre Direitos Humanos (1988), na Declaração da Conferência das Nações Unidas sobre Meio Ambiente e Desenvolvimento (Rio de Janeiro, 1992) e na Declaração da Cúpula dos Povos (Rio de Janeiro, 2012).

A Declaração da Conferência das Nações Unidas sobre Meio Ambiente Humano $^{413}$, realizada em 1972 na cidade de Estocolmo, dispôs em seu primeiro princípio:

${ }^{410}$ GAVIÃO FILHO, Anízio Pires. Direito fundamental ao ambiente. Porto Alegre: Livraria do Advogado Editora, 2005. p. 36.

${ }^{411}$ FENSTERSEIFER, Tiago. Direitos fundamentais e proteção do ambiente: a dimensão ecológica da dignidade humana no marco jurídico-constitucional do estado socioambiental de direito. Porto Alegre: Livraria do Advogado Editora, 2008. p. 167.

${ }^{412}$ Ibidem.

${ }^{413}$ Declaração da Conferência das Nações Unidas sobre Meio Ambiente Humano. Estocolmo: 5 a 16 de junho de 1972. Disponível em: http://www.onu.org.br/rio20/img/2012/01/estocolmo1972. pdf. Acessado em: 27.08.2012. 
O homem tem o direito fundamental à liberdade, à igualdade e ao desfrute de condições de vida adequadas em um meio ambiente de qualidade tal que lhe permita levar uma vida digna e gozar de bem-estar, tendo a obrigação de proteger e melhorar o meio ambiente para as gerações presentes e futuras.

Por seu turno, a Declaração da Conferência das Nações Unidas sobre Meio Ambiente e Desenvolvimento ${ }^{414}$, havida no Rio de Janeiro em 1992, reafirmou a fundamentalidade do direito ao ambiente no plano internacional:

Os seres humanos constituem o centro das preocupações relacionadas com o desenvolvimento sustentável. Têm direito a uma vida saudável e produtiva, em harmonia com a natureza.

O direito fundamental ao meio ambiente consiste em acréscimo ao estatuto dos direitos fundamentais da humanidade, de modo que sua proteção tende a ser realizada por mecanismos constitucionais que assegurem a sua irrenunciabilidade. Assim, no Brasil, o direito ao meio ambiente, por se tratar de direito fundamental, possui eficácia direta e abrangente para todo o ordenamento jurídico, na forma em que preceitua o $\S 1^{\circ}$ do art. $5^{\circ} \mathrm{da} \mathrm{CF} / 88$ sobre a aplicabilidade imediata das normas definidoras de direitos fundamentais. De sua matriz subjetiva resulta que o direito ao ambiente é um direito conferido aos cidadãos de cobrarem contraprestações ao Estado para a proteção de seu direito subjetivo e, como tal, encontra-se juridicamente blindado contra a ação do poder constituinte reformador pela limitação material encartada no art. $60, \S$ $4^{\circ}$, IV da CF/88. Portanto, o direito fundamental ao meio ambiente consiste em cláusula pétrea protegida contra a atuação do poder constituinte derivado que pretenda suprimir ou diminuir de qualquer modo os seus conteúdos.

A limitação material imposta pelas cláusulas pétreas consiste em um dos fundamentos que empresta sustentação à admissão de um princípio da vedação do retrocesso em matéria ambiental. O poder constituinte reformador não poderá diminuir o direito ou as garantias à preservação do direito fundamental ao meio ambiente porque em assim agindo estará incidindo em violação do núcleo duro da Constituição Federal composto por todos os direitos fundamentais que se relacionam com os direitos e garantias individuais, numa interpretação mais abrangente das cláusulas pétreas. A limitação à liberdade do poder constituinte

\footnotetext{
${ }^{414}$ Declaração da Conferência das Nações Unidas sobre Meio Ambiente e Desenvolvimento. Rio de Janeiro: 3 a 14 de junho de 1992. Disponível em: http://www.defensoria.sp.gov.br/dpesp/Repositorio/31/Documentos/Declara\%C3\%A7\%C3\%A3o\%20do\%20RJ\%20sobre\%20meio\%20ambiente\%20e\%20desenvolvimento\%20-\%201992.pdf. Acessado em: 27.08.2012.
} 
derivado em definir os conteúdos e procedimentos utilizados para a proteção do meio ambiente é traçada de forma expressa pelas cláusulas pétreas, mas se dirige indiretamente também ao legislador ordinário quando da definição por este de conteúdos e instrumentos que possa compreender como apropriados para a defesa do meio ambiente.

Para além da eficácia indireta das cláusulas pétreas sobre a atuação do legislador ordinário no tratamento de matéria ambiental, há uma racionalidade limitativa contemplada pela Constituição Federal em vista desse legislador situada no próprio conteúdo do direito ao meio ambiente equilibrado enquanto direito necessário para permitir a sadia qualidade de vida. A definição do direito ao meio ambiente levada a cabo pela Constituição Federal é peculiar porque de forma expressa vincula este direito como essencial à vida humana, decorrendo daí, uma especial situação jurídica que impõe colocar este direito a salvo de alterações infraconstitucionais que diminuam o grau de eficácia já obtida, seja por força da própria Constituição, seja pelas legislações precedentes. Nesse plano, nenhuma ação legislativa que importe em decréscimo do direito fundamental ao meio ambiente poderá ser considerada constitucional. Dessa racionalidade defensiva contida no próprio direito fundamental ao meio ambiente se encontra o argumento para o reconhecimento de um princípio que proíba o retrocesso em matéria ambiental.

Melhor compreensão de uma proposta de princípio limitador do retrocesso ambiental se obtém ao analisar os tipos de posições jurídicas que o direito ao meio ambiente possibilita emanar. Na perspectiva de um direito fundamental completo $^{415}$ o direito fundamental ao meio ambiente contempla um complexo feixe de posições jusfundamentais que abarcam tanto o direito de se exigir do Estado posições prestacionais para aumentar a proteção do ambiente, como posições negativas que impliquem em condutas de abstenção do Estado, sendo estas posições que emprestam ainda maior fundamento para o estabelecimento de um princípio limitador do retrocesso ambiental.

\section{O PRINCÍPIO DA VEDAÇÃO DO RETROCESSO AMBIENTAL: COMPREENSÃo A PARTIR dA PERSPECTIVA do DIREITO AO AMBIENTE COMO UM DIREITO FUNDAMENTAL COMPLETO}

Os direitos fundamentais apresentam um caráter duplo ao consubstanciar tanto direitos subjetivos quanto elementos de ordem objetiva que se relacionam e se fortalecem ${ }^{416}$. O direito fundamental ao meio ambiente configura direito

\footnotetext{
${ }^{415}$ ALEXY, Robert. Teoria dos direitos fundamentais. Trad. Virgílio Afonso da Silva. São Paulo: Malheiros, 2011. p. 443.

${ }^{416}$ HESSE, Konrad. Elementos de direito constitucional da República Federativa da Alemanha. Tradução de Luís Afonso Heck. Porto Alegre: Fabris, 1998. p. 228. In: GAVIÃO FILHO, Anízio
} 
subjetivo no sentido de os indivíduos poderem pleitear ao Estado o direito de defesa contra os atos lesivos ao ambiente e, concomitantemente, dever de ordem objetiva no sentido de expressar as incumbências a cargo do Estado que se dirijam a assegurar a todos a realização do ambiente ecologicamente equilibrado ${ }^{417}$. $\mathrm{O}$ art. $225, \S 1^{\circ}$, da $\mathrm{CF} / 88$ fixa objetivos estatais para a realização do direito ao ambiente de forma vinculante para o legislador e também para os Poderes Executivo e Judiciário ${ }^{418}$. As dimensões objetiva e subjetiva do direito ao ambiente coexistem e se complementam e desta dupla configuração é que se poderá compreender o direito ao ambiente com um direito fundamental completo.

$\mathrm{O}$ direito fundamental completo ou como um todo é proposto por Alexy ${ }^{419}$ para indicar um feixe de posições definitivas e de posições prima facie envolvendo os cidadãos e o Estado. Da relação entre o Estado e os cidadãos podem surgir algumas espécies de direitos que bem expressam a complexidade do direito ao meio ambiente: os direitos de defesa, referentes ao direito de o Estado se abster de determinadas intervenções no ambiente; os direitos à proteção, atinentes a que o Estado proteja o titular do direito em vista da intervenção de terceiros que importem em prejuízos ao ambiente; os direitos ao procedimento, pertinentes a que o Estado defira condições de participação ao indivíduo nos procedimentos importantes para o meio ambiente; e os direitos de prestação, referentes a prestações fáticas que devem ser levadas a cabo pelo próprio Estado para a promoção e a proteção ambiental $^{420}$. Sobre o tema, Alexy pontua:

Um direito fundamental ao meio ambiente corresponde mais àquilo que acima se denominou 'direito fundamental completo'. Ele é formado por um feixe de posições de espécies bastante distintas. Assim, aquele que propõe a introdução de um direito fundamental ao meio ambiente, ou que pretende atribuí-lo por meio de interpretação a um dispositivo de direito fundamental existente, pode incorporar a esse feixe, dentre outros, um direito a que o Estado se abstenha de determinadas intervenções no meio ambiente (direito de defesa), um direito a que o Estado proteja o titular do direito fundamental contra intervenções de terceiros que sejam lesivas ao meio ambiente (direito a proteção), um direito a que o Estado inclua o titular do direito fundamental nos procedimentos relevantes para o meio ambiente (direito a procedimentos) e um direito a que o próprio Estado tome medidas fáticas benéficas ao meio ambiente (direito

Pires. Direito fundamental ao ambiente. Porto Alegre: Livraria do Advogado Editora, 2005. p. 38.

${ }^{417}$ GAVIÃO FILHO. Op. Cit. p. 39.

${ }^{418}$ Ibidem.

${ }^{419}$ ALEXY. Op. cit. p. 248.

${ }^{420}$ Ibidem, p. 443. 
a prestação fática). Além disso, as posições propostas ou alegadas podem dizer respeito a direitos prima facie ou a direitos definitivos. $\mathrm{O}$ mesmo vale para outros direitos suscitados por meio da utilização da expressão 'direitos fundamentais sociais'. ${ }^{421}$

$\mathrm{Na}$ perspectiva que compreende o ambiente enquanto um direito do qual derivam relações jurídicas diversificadas, Canotilho observa que o fato de se considerar uma face objetiva do direito ao ambiente identificada com as normas-tarefa ou normas-fim, respeitantes à existência de autênticos deveres jurídicos dirigidos ao Estado, não obsta a possibilidade de se contemplar uma dimensão subjetiva do direito ao ambiente ${ }^{422}$. Conforme o constitucionalista, o reconhecimento de uma face subjetiva do direito ao ambiente é imprescindível porque "só o reconhecimento de um direito subjectivo ao ambiente permitirá, em termos jurídico-constitucionais, recortar o ambiente como bem jurídico autónomo, não dissolvido na proteção de outros bens constitucionalmente relevantes "423. Para o autor, o direito ao ambiente foi reconhecido na Constituição portuguesa como um direito subjetivo do tipo dos direitos econômicos, sociais e culturais e na Constituição espanhola como direito fundamental informador ${ }^{424}$. Conforme o doutrinador português, o reconhecimento do direito fundamental ao meio ambiente enquanto direito subjetivo do tipo dos direitos econômicos, sociais e culturais permite emergirem diferentes momentos do direito ao ambiente, os quais identifica como direitos procedimentais ambientais - relativos aos direitos dos particulares de exigirem do Estado informação, participação e direitos de ação judicial - direitos à proteção do ambiente - referentes aos direitos outorgados aos indivíduos de cobrarem do Estado combater os perigos concretos que incidem sobre o ambiente, bem como protegê-los contra ações dos demais indivíduos lesivas ao ambiente - e direitos a prestações - enquanto direitos dos particulares a prestações Estatais específicas, as quais enfrentam o problema de não decorrerem diretamente da Constituição, porém, podem ser estabelecidas pela lei ${ }^{425}$.

Nessa ordem de ideias, o direito fundamental completo não afasta a coexistência de uma dimensão subjetiva do direito ao meio ambiente, a qual se reporta a que os indivíduos tenham legitimidade para cobrar do Estado uma atuação defensiva e protetiva do meio ambiente e, ainda, de uma dimensão

${ }^{421}$ ALEXY. Op. Cit. p. 443.

${ }^{422}$ CANOTILHO. José Joaquim Gomes. O direito ao ambiente como direito subjectivo. In: . Estudos sobre direitos fundamentais. Coimbra: Coimbra Editora. São Paulo: Revista dos Tribunais, 2008. p. 181.

${ }^{423}$ Ibidem.

${ }^{424}$ Ibidem. p. 186.

${ }^{425}$ Ibidem. pp. 187-188. 
objetiva, da qual advém que é dever do próprio Estado adotar providências para promover o ambiente. Essas dimensões estão relacionadas ao que Alexy classifica como direitos de defesa e direitos à proteção - direito subjetivo dos indivíduos em face do Estado - e direitos a prestações - dever objetivo do Estado de agir promovendo o direito ao ambiente por decorrência das normas de direitos fundamentais.

Os direitos de defesa se relacionam ao direito subjetivo ou a pretensões, o que Alexy convencionou denominar como "direito a algo"426, a fim de estabelecer com maior clareza a situação relacional entre Estado e indivíduo que necessariamente deve estar contemplada na perspectiva de um direito fundamental completo.

Os direitos de defesa concernem a que se exija do Estado agir de modo a não obstar o exercício do direito pelo seu titular; não afetar determinadas situações do titular do direito; ou, ainda, não eliminar posições do titular do direito $^{427}$. O primeiro aspecto diz respeito a que o Estado deve abster-se de concretizar condutas que de algum modo venham a impor prejuízos ao meio ambiente, causando, assim, decréscimos ao exercício do direito ao meio ambiente pelo seu titular. A esta acepção estão relacionadas, sobretudo, as condutas administrativas que de modo positivo ou negativo imponham óbice a atividades de proteção ou de promoção do meio ambiente. O segundo aspecto tem em conta as condutas negativas administrativas que se devam exigir do Estado para que o meio ambiente não sofra prejuízos em sua proteção, portanto, se relaciona a possibilidade de cobrar um não agir estatal, como o de não conceder licenças operacionais para atividades poluentes sem atentar ao prévio estudo e relatório de impacto ambiental. A terceira acepção refere-se a que o Estado se abstenha, sobretudo, de levar a cabo produção legislativa que importe em prejuízo ao direito fundamental ao meio ambiente ecologicamente equilibrado.

O princípio da vedação do retrocesso ambiental analisado sob o enfoque dos direitos de defesa garante ao indivíduo o direito de cobrar ao Estado condutas legislativas ou administrativas de não redução do patrimônio jurídico ambiental.

Sob o aspecto dos direitos de defesa é possível exigir-se ao Estado atuação legislativa adequada à não eliminação de uma posição jurídica albergada pela Constituição ou pela legislação infraconstitucional. Importante estabelecer que a eliminação de uma posição jurídica não se confunde coma eliminação do dispositivo normativo que veicula uma determinada norma de direito fundamental. A afetação da posição jurídica pode se verificar de variadas formas, podendo, sim, haver a supressão do próprio dispositivo constitucional

\footnotetext{
${ }^{426}$ Ibidem. p. 193.

${ }^{427}$ GAVIÃO FILHO. Op. cit. p. 49.
} 
ou infraconstitucional que veicule determinada norma de direito fundamental, ou ainda, a supressão de certos conteúdos que garantam as posições jurídicas referentes ao meio ambiente. A respeito da diferença existente entre disposições de direitos fundamentais e normas de direitos fundamentais, pertinentes as considerações de Alexy:

Se se conjugam ambos os critérios orientados pelo texto da Constituição, poder-se-ia, provisoriamente, definir os conceitos de disposição e de norma de direitos fundamentais da seguinte maneira: disposições de direitos fundamentais são aquelas contidas nas disposições dos arts. $1^{\circ}$ ao 19 da Constituição alemã, bem como as disposições garantidoras de direitos individuais dos arts. 20, $\S 4^{\circ}, 33,38,101,103$ e 104 da Constituição alemã. Normas de direitos fundamentais são as normas diretamente expressas por essas disposições ${ }^{428}$.

Apenas o poder constituinte reformador teria competência para abolir os próprios dispositivos normativos que veiculam as normas de direitos fundamentais relativos ao ambiente, no caso, os dispositivos do art. 225 da Constituição Federal. Poderia, ainda, o poder constituinte derivado suprimir as normas de direitos fundamentais veiculadas pelos dispositivos de direitos fundamentais mediante a supressão de determinadas posições jurídicas do direito ao meio ambiente que são veiculadas pelos dispositivos constitucionais. Tal intervenção seria indevida, uma vez que suprime cláusula pétrea, nos termos do art. $60, \S 4^{\circ}, \mathrm{IV}$, da Constituição Federal e consiste em violação ao princípio da vedação do retrocesso.

O legislador ordinário, por seu turno, não possui competência para eliminar os dispositivos que veiculam normas de direitos fundamentais constantes da própria Constituição, porém, pode atuar suprimindo ou diminuindo as normas de direitos fundamentais veiculadas pelos dispositivos da Constituição mediante legislação infraconstitucional quando esta contemplar normas de direitos fundamentais atribuídas ${ }^{429}$. As normas de direitos fundamentais atribuídas são normas infraconstitucionais que possuem fundamentação nas normas constitucionais e por isso guardam consonância com esta. Se o produto do processo legislativo ordinário implicar em prejuízo das posições jurídicas sustentadas pelas normas do direito fundamental ao meio ambiente, estará consolidado o retrocesso ambiental. O que é de inestimável importância é considerar que o legislador ordinário também produz normas de direitos fundamentais - normas de direitos fundamentais atribuídas - que

\footnotetext{
${ }^{428}$ ALEXY. Op. cit. p. 68.

${ }^{429}$ Ibidem. p. 69.
} 
se relacionam com as normas fundamentais diretamente constitucionais e a partir do momento que as estabelece resta vinculado a não as suprimir ou diminuir a sua efetividade.

É possível observar, contudo, que a supressão de normas de direitos fundamentais levada a cabo pelo legislador ordinário é facilitada pela conjuntura de menor complexidade do processo legislativo, sendo recorrente o Estadolegislador não apenas acrescentar o patrimônio jurídico ambiental pela criação de novas normas de direitos fundamentais, porém, de forma inversa, diminuí-lo mediante a relativa simplicidade ensejada pelo processo legislativo ordinário.

Segundo Gavião Filho:

Essa proibição de retrocesso do ambiente obsta tanto a supressão como o esvaziamento das normas constitucionais ou infraconstitucionais que consolidam posições jurídicas relativas ao direito fundamental ao ambiente. Aliás, nesse sentido, pode-se afirmar, com base na norma do art. $1^{\circ}$, III, da Constituição, segundo a qual o Estado democrático de direito brasileiro tem como fundamento a dignidade da pessoa humana, e no fato de que o direito ao ambiente é direito fundamental, que as normas constitucionais relativas à proteção do ambiente estão cobertas pelo art. $60, \S 4^{\circ}$, da Constituição, que veda proposta de emenda constitucional tendente a abolir direitos e garantias individuais. Assim, pode ser formulado o enunciado no sentido de que será inconstitucional a sobrevinda de norma constitucional que suprimir ou esvaziar qualquer das normas hoje existentes na ordem constitucional para a proteção do ambiente. [...] A proibição de retrocesso faz-se sentir mais incisivamente diante do legislador infraconstitucional, vedando a dação legislativa ordinária implicativa de redução substancial de posições jurídicas já solidificadas no ordenamento jurídico ${ }^{430}$.

Quanto ao aspecto do direito a prestações, o princípio da vedação do retrocesso ambiental se relaciona com um dever objetivo do Estado em promover ações que acrescentem proteção e desenvolvimento ao meio ambiente ecologicamente equilibrado adotado pela Constituição enquanto valor objetivo. A perspectiva objetiva do direito ao ambiente importa em dever de não retrocesso mediante a prática de ações estatais que preservem os conteúdos do meio ambiente. Tais prestações podem ser de ordem fática ou normativa. Nesse sentido, Alexy observa que o direito a prestações se opõe ao conceito de direito de defesa, na medida em que o Estado deve adotar uma conduta positiva por intermédio de ações estatais diversas que abrangem desde a proteção dos

$\overline{{ }^{430} \text { GAVIÃO FILHO. Op. cit. pp. } 49-50 .}$ 
cidadãos contra outros cidadãos por meio de produção legislativa e alcança ainda prestações de cunho material, assinalando que no caso de muitos direitos sociais que são considerados, por excelência, direitos a prestações, há um feixe de posições jurídicas que dizem respeito em parte a prestações fáticas e em parte a prestações normativas, sendo este o caso do direito ao meio ambiente ${ }^{431}$.

Sobre a dimensão objetiva do direito ao meio ambiente, Vasco Pereira da Silva sustenta:

A 'Constituição do Ambiente', na sua dimensão objectiva, implica, desde logo, a consideração de que os princípios e valores ambientais representam bens jurídicos fundamentais, que se projectam na actuação quotidiana de aplicação e de concretização do direito, para além de imporem objectivos e finalidades que não podem ser afastados pelos poderes públicos e que é sua tarefa realizar. O que, entre outras coisas, significa: a) que o legislador tem o dever de emitir as normas necessárias à realização dos princípios e das disposições constitucionais relativas ao ambiente. Dever este que, se não for atempadamente realizado, implica a existência de uma inconstitucionalidade por omissão, da mesma forma como o seu cumprimento deficiente, violando as estatuições ou os parâmetros da lei fundamental, é gerador de inconstitucionalidade por acção; b) que a Administração se encontra vinculada pelas normas e princípios constitucionais em matéria ambiental, uma vez que o princípio da legalidade da actuação administrativa não significa apenas a submissão à lei, mas ao direito no seu conjunto. Diga-se, a propósito, que as normas e os princípios constitucionais são sobretudo importantes quando se tratar do exercício de poderes discricionários, já que aí eles assumem a dimensão de vinculações auntónomas directamente aplicáveis, fornecedoras de critérios de decisão e estabelecendo limites para a margem de apreciação e de decisão da Administração, os quais, se violados, originam a ilegalidade da actuação administrativa (por vício de violação de lei); c) que os tribunais, na sua tarefa de julgamento dos litígios, devem concretizar as normas e os princípios constitucionais em matéria de ambiente, tanto no que respeita à interpretação e integração das lacunas da lei, quer relativamente aos juízos de prognose ou de ponderação de valores e de interesses (que não podem esquecer a consideração dos 'bens jurídicos' ambientais), quer ainda no que concerne à adaptação, ou mesmo à criação, dos meios processuais adequados a garantir a tutela plena e efectiva dos valores fundamentais em questão $0^{432}$.

${ }^{431}$ ALEXY. Op. Cit. p. 442.

${ }^{432}$ SILVA, Vasco Pereira da. Verde cor do direito. Lições de direito do ambiente. Coimbra: 
O direito a prestações abrange todos os poderes estatais que devem agir, cada qual dentro de sua competência de modo a ampliarem a tutela ao meio ambiente. As prestações fáticas, normativas e mesmo judiciárias podem demandar grande margem de discricionariedade, o que implica em reconhecer que os indivíduos não possam controlar, pelo menos a priori, a forma e o conteúdo das prestações que se dirijam a ampliar o direito ao meio ambiente, a menos quando o próprio ordenamento jurídico não individualize quais ações são devidas. Contudo, a possibilidade de exigir ao Estado num sentido geral posições ativas para a defesa e proteção do ambiente é amplamente reconhecida pela doutrina como um dever objetivo contemplado pela ordem constitucional. Consoante Canotilho, o ambiente é constitucionalmente reconhecido como tarefa ou fim do Estado, impondo-se a este autênticos deveres jurídicos que lhe subtraem a discricionariedade sobre proteger ou não o ambiente, havendo apenas uma clara disposição constitucional imperativa no sentido de que deve protegê-10 ${ }^{433}$.

Segundo Sarlet, o princípio da proporcionalidade atua de forma importante na análise da função dos deveres de proteção do Estado em relação aos direitos fundamentais, considerando que a proporcionalidade opera tanto na forma de proibição de excesso como também atua proibindo a insuficiência, podendo o Estado violar o dever de proteção pela omissão de medidas destinadas a tornar efetivo esse dever ou, ainda, quando atua de modo insatisfatório ${ }^{434}$.

O princípio da vedação do retrocesso ambiental está, portanto, atrelado à compreensão do direito ao meio ambiente enquanto direito fundamental completo caracterizado por um complexo feixe de posições jurídicas envolvendo os indivíduos e o Estado. Na dimensão negativa do direito fundamental ao meio ambiente encontram esteio os direitos de defesa do indivíduo e da coletividade de exigirem do Estado a abstenção de condutas que importem em diminuição da esfera de fruição e de proteção deste direito fundamental. Da dimensão positiva do direito fundamental ao meio ambiente advém o direito dos indivíduos de cobrarem do Estado ações prestacionais para a ampliação da tutela do ambiente.

Almedina, 2003. pp. 63-64.

${ }^{433}$ CANOTILHO, José Joaquim Gomes. O direito ao ambiente como direito subjectivo. In: Estudos sobre direitos fundamentais. Coimbra: Coimbra Editora. São Paulo: Revista dos Tribunais, 2008. p. 181.

${ }^{434}$ SARLET, Ingo Wolfgang. Direitos fundamentais sociais, 'mínimo existencial' e direito privado. Breves notas sobre alguns aspectos da possível eficácia dos direitos sociais nas relações entre particulares. In: GALDINO, Flávio; SARMENTO, Daniel (Orgs.). Direitos fundamentais. Estudos em homenagem a Ricardo Lobo Torres. Rio de Janeiro: Renovar, 2006. pp. 581-582. 


\section{O PRINCÍPIO DA VEDAÇÃo DO RETROCESSO AMBIENTAL ENQUANTO PRINCÍPIO CONSTITUCIONAL IMPLÍCITO}

O princípio da vedação do retrocesso não possui previsão constitucional explícita no ordenamento jurídico brasileiro, extraindo sua legitimidade da consideração de que os avanços percebidos em relação aos direitos fundamentais individuais e sociais constituem acréscimos ao patrimônio jurídico de seus titulares e, uma vez implementados, não podem ser subtraídos, porém apenas acrescentados, encerrando, assim, um dever geral de progressividade.

A vedação do retrocesso tem razão em que não é possível retroceder nas conquistas que se fizeram ao longo da história da humanidade na construção de um patrimônio político-jurídico que teve por finalidade a salvaguarda da dignidade pessoa humana ${ }^{435}$. Enquanto princípio constitucional implícito na ordem jurídica brasileira, a vedação do retrocesso se propõe a proteger os direitos individuais e, principalmente, os direitos sociais legados pelo Estado Social de Direito, se relacionando com os princípios constitucionais da segurança jurídica, da proteção da confiança, do direito adquirido, do ato jurídico perfeito e da coisa julgada, além da garantia às limitações materiais à reforma constitucional ${ }^{436}$. Segundo Sarlet:

A estabilidade institucional (incluindo a estabilidade jurídica) é fundamental para o exercício dos direitos fundamentais do cidadão, na medida em que a dignidade humana não restará suficientemente respeitada e protegida onde as pessoas estejam expostas a tal nível de instabilidade jurídica que não estejam mais em condições de, com um mínimo de segurança e tranquilidade, confiar nas instituições sociais e estatais (incluindo o Direito) e numa certa estabilidade das suas próprias posições jurídicas ${ }^{437}$.

A proibição do retrocesso se dirige a assegurar estabilidade ao patrimônio dos direitos fundamentais que a humanidade agregou ao longo do tempo e, não obstante, pretende conferir a tal patrimônio jusfundamental um crescente grau de eficácia e efetividade, no sentido de não se restringir a proteger as posições jurídicas fundamentais expressas nas normas de direitos fundamentais,

435 _ FENSTERSEIFER, Tiago. Direito constitucional ambiental. Estudos sobre a Constituição, os direitos fundamentais e a proteção do ambiente. Porto Alegre: Livraria do Advogado, 2011. p. 191.

${ }^{436}$ SARLET, Ingo Wolfgang. A eficácia dos direitos fundamentais. Porto Alegre: Livraria do Advogado, 2005. p. 433 e ss.

${ }^{437}$ Ibidem. 
porém, se volta a conferir que os conteúdos protegidos pelas normas sejam progressivamente agregados. Nesse sentido, observam Sarlet e Fensterseifer:

Aproibição do retrocesso, nesse cenário, diz respeito mais especificamente a uma garantia de proteção dos direitos fundamentais (e da própria dignidade da pessoa humana) contra a atuação do legislador, tanto no âmbito constitucional quanto - e de modo especial - infraconstitucional (quando estão em causa medidas legislativas que impliquem supressão ou restrição no plano das garantias e dos níveis de tutela dos direitos já existentes), mas também proteção em face da atuação da administração pública. A proibição do retrocesso, de acordo com o entendimento consolidado na doutrina, consiste em um princípio constitucional implícito, tend o como fundamento constitucional, entre outros, o principio do Estado (Democrático e Social) de Direito, o princípio da dignidade da pessoa humana, o princípio da máxima eficácia e efetividade das normas definidoras de direitos fundamentais, o princípio da segurança jurídica e seus desdobramentos, o dever de progressividade em matéria de direitos sociais, econômicos, culturais e ambientais (DESCA), apenas para citar os mais relevantes fundamentos jurídico-constitucionais invocados ${ }^{438}$.

Na seara do direito ambiental, o princípio da vedação do retrocesso é amplamente reconhecido pela doutrina como princípio constitucional implícito e imprescindível para assegurar o direito humano à sadia qualidade de vida num meio ambiente ecologicamente equilibrado (art. 225, caput, da CF/88). Tal reconhecimento, contudo, recebe a crítica do doutrinador Celso Antonio Pacheco Fiorillo para quem é despicienda a incorporação do princípio no direito brasileiro porque a finalidade última do direito ao meio ambiente é assegurar efetividade à dignidade da pessoa humana, resolvendo-se, portanto, na indeclinabilidade da dignidade humana, enquanto princípio expressamente reconhecido pela ordem constitucional, eventual supressão do direito ao meio ambiente levada a cabo pelo legislador ordinário. Conforme Fiorillo:

Trata-se de dar efetividade aos Direitos Fundamentais da Pessoa Humana (art. $1^{\circ}$, III, da CF), não cabendo a qualquer pessoa, inclusive ao administrador público preterir, o Piso Vital Mínimo (Art. $6^{\circ}$ da Constituição Federal) na medida em que não se trata de "opção do governante" ou mesmo - como pretendem argumentar alguns, ainda com o olhar vinculado ao vetusto direito administrativo - de "opção discricionária do administrador", uma vez que não estamos cuidando

${ }^{438}$ SARLET, Ingo Wolfgang; FENSTERSEIFER, Tiago. (2011) Op. Cit. p. 192. 
de juízo discricionário, muito menos de tema a depender unicamente da vontade política.

Dessa feita, temos então que o art. $6^{\circ}$ da Constituição fixa um piso vital mínimo de direitos que devem ser assegurados pelo Estado (que o faz mediante a cobrança de tributos), para o desfrute da sadia qualidade de vida.

Assim não existe qualquer necessidade em se transportar para o Direito Ambiental Constitucional o chamado "princípio" da vedação do retrocesso nos moldes importados de culturas alienígenas ${ }^{439}$.

A compreensão de que o princípio da vedação do retrocesso não exerce maior função que o princípio da dignidade da pessoa humana para garantir as conquistas relacionadas ao direito fundamental ao meio ambiente ecologicamente equilibrado, contudo, não parece o argumento mais adequado para descaracterizar a serventia e efetividade da vedação do retrocesso ambiental no direito brasileiro. A dignidade da pessoa humana funciona como princípio-mestre na Constituição brasileira a partir do qual se erigem todos os direitos fundamentais. É inquestionável que os direitos fundamentais tenham assento no princípio da dignidade da pessoa humana que deve reger as políticas públicas voltadas ao desenvolvimento da saúde, educação, trabalho e habitação, dentre os direitos sociais que imediatamente se conectam com a garantia do mínimo existencial. $\mathrm{O}$ direito ao meio ambiente, igualmente, como direito do tipo dos direitos sociais, culturais e econômicos, assenta sua fundamentação no princípio da dignidade da pessoa humana, cabendo ao Estado, prover as políticas públicas ambientais essenciais para assegurar o mínimo existencial socioambiental, compreendido enquanto as necessidades ambientais indispensáveis para a fruição de uma sadia qualidade de vida. $\mathrm{O}$ princípio da vedação do retrocesso ambiental, contudo, diz respeito, mais especificamente, a uma obrigação voltada ao legislador de não "retroceder" em relação aos avanços já conquistados na seara do mínimo existencial socioambiental, funcionando, portanto, como uma espécie de instrumento jurídico-constitucional para a garantia dos conteúdos ambientais assegurados pelo princípio da dignidade da pessoa humana. Desse modo, o princípio da dignidade da pessoa humana não reabsorve todos os princípios que com ele se conectam, mas, pelo contrário, os auxilia a angariar, de forma harmônica

${ }^{439}$ FIORILlO, Celso Antonio Pacheco. O denominado "princípio" da vedação do retrocesso, suas atuais referencias no Supremo Tribunal Federal e eventuais aplicações no direito ambiental constitucional brasileiro. Disponível em: http://www.saraivajur.com.br/menuEsquerdo/ doutrinaArtigosDetalhe.aspx?Doutrina=1167. Acessado em: 20.08.2012. 
com os demais princípios constitucionais, projeções de independência que se propõem a assegurar um direito fundamental peculiar que os identificam.

Sobretudo, em relação ao meio ambiente, o princípio da vedação do retrocesso agrega importância singular em razão da urgência de se considerar o esgotamento dos recursos ambientais e o dever de preservação e proteção do ambiente para as futuras gerações. A escassez dos recursos naturais é uma realidade insuperável que se encontra diretamente relacionada com o processo de desenvolvimento. Os recursos naturais, uma vez consumidos no processo de transformação da matéria, não se colocam uma segunda vez à disposição, sendo constatável que o sistema econômico é dissipativo e não se auto-perpetua ${ }^{440}$. Do mesmo modo, o desenvolvimento tecnológico está cada vez mais apto a absorver a matéria e energia existentes na natureza gerando processos irreversíveis de degradação ambiental que afetam diretamente a disponibilidade de recursos para as gerações futuras. O princípio da vedação do retrocesso ambiental atua como mecanismo de controle social e jurídico do desenvolvimento e de suas consequências de consumação dos recursos naturais destinado a impor ao Estado políticas voltadas ao desenvolvimento sustentável que tenham em conta, além da preservação dos recursos existentes, uma melhoria da qualidade de vida ambiental para as gerações presentes e futuras.

Canotilho relaciona o dever de progressividade aos instrumentos jurídicos que se colocam à disposição do Estado para a proteção do ambiente, observando que as normas-tarefa ou normas-fim possuem dinamicidade:

As normas-fim e normas-tarefas ambientalmente relevantes são normas constitucionais impositivas. Por isso, impõe ao legislador e a outras entidades (autonomias locais) o dever de adoptar medidas de proteção adequadas à proteção do ambiente. Mas, não apenas isso. A doutrina salienta que as normas-fim ecológicas e ambientais constitucionalmente consagradas têm um carácter dinâmico que implica uma actualização e um aperfeiçoamento permanente dos instrumentos jurídicos destinados à proteção do ambiente perante os novos perigos de agressões ecológicas ${ }^{441}$.

A Declaração da Conferência das Nações Unidas sobre o Ambiente Humano (Estocolmo, 1972), em seu princípio 3', determina o dever de "manter, e sempre que possível, restaurar ou melhorar a capacidade da terra em produzir recursos vitais renováveis”. O parágrafo $1^{\circ}$ do art. $2^{\circ}$ do Pacto Internacional dos Direitos Econômicos, Sociais e Culturais de 1966, igualmente, contempla cláusula de progressividade atrelada ao direito fundamental ao meio ambiente:

\footnotetext{
${ }^{440}$ DERANI, Cristiane. Direito ambiental econômico. São Paulo: Max Limonad, 2001. p.143.

${ }^{441}$ CANOTILHO, José Joaquim Gomes. Op. cit. p. 182.
} 
Cada um dos Estados Partes no presente Pacto compromete-se a agir, quer com o seu próprio esforço, quer com a assistência e cooperação internacionais, especialmente nos planos econômico e técnico, no máximo dos seus recursos disponíveis, de modo a assegurar progressivamente o pleno exercício dos direitos reconhecidos no presente Pacto por todos os meios apropriados, incluindo em particular por meio de medidas legislativas ${ }^{442}$.

O princípio da vedação do retrocesso se conecta com a cláusula de progressividade na medida em que o Estado possui o dever de, por intermédio de suas práticas legislativas, provocar uma melhoria da qualidade de vida ambiental. Tal tarefa importa em acrescentar os conteúdos do direito fundamental ao meio ambiente de modo a ampliar o objeto de sua proteção e em criar novos instrumentos jurídicos de tutela ambiental. A limitação ao exercício do poder legislativo para suprimir conteúdos e garantias do direito fundamental ao meio ambiente em decorrência de sua vinculação ao princípio da vedação do retrocesso é ressaltada nas palavras de Molinaro:

O princípio de proibição da retrogradação socioambiental, como afirmamos, embora restrinja a afetação da liberdade parlamentar, praticada nos limites do mínimo, remanescendo-lhe o excedente, no entanto, agora veda-lhe o poder de desconstituição, mesmo do excedente, desde que já consolidado ${ }^{443}$.

A despeito do reconhecimento pelos tribunais acerca do princípio da proibição do retrocesso ambiental, o Superior Tribunal de Justiça pronunciou-se:

[...] o relaxamento, pela via legislativa, das restrições urbanísticoambientais convencionais, permitido na esteira do ius variandi de que é titular o Poder Público, demanda, por ser absolutamente fora do comum, ampla e forte motivação lastreada em clamoroso interesse público, postura incompatível com a submissão do Administrador a necessidades casuísticas de momento, interesses especulativos ou vantagens comerciais dos agentes econômicos. O exercício do ius variandi, para flexibilizar

\footnotetext{
${ }_{442}^{42}$ Pacto Internacional sobre os Direitos Econômicos, Sociais e Culturais adotado pela Assembléia Geral das Nações Unidas, de 16 de Dezembro de 1966. Disponível em: http://www.oas.org/dil/ port/1966\%20Pacto\%20Internacional\%20sobre\%20os\%20Direitos\%20Econ\%C3\%B3micos, \%20 Sociais\%20e\%20Culturais.pdf. Acessado em 27.08.2012.

${ }^{443}$ MOLINARO, Carlos Alberto. Direito ambiental. Proibição de retrocesso. Porto Alegre: Livraria do Advogado, 2007. p. 114.
} 
restrições urbanístico-ambientais contratuais, haverá de respeitar o ato jurídico perfeito e o licenciamento do empreendimento, pressuposto geral que, no Direito Urbanístico, como no Direito Ambiental, é decorrência da crescente escassez de espaços verdes e dilapidação da qualidade de vida nas cidades. Por isso mesmo, submete-se ao princípio da não-regressão (ou, por outra terminologia, princípio da proibição de retrocesso), garantia de que os avanços urbanístico-ambientais conquistados no passado não serão diluídos, destruídos ou negados pela geração atual ou pelas seguintes ${ }^{444}$.

Os reflexos da vedação do retrocesso para o meio ambiente se demonstram de maneira mais flagrante que em relação aos direitos sociais. A partir da concepção de que o direito ao meio ambiente consiste em direito fundamental completo, conforme defendido por Alexy, sua carga de imperatividade perante o Estado e os cidadãos é mais intensa devido a que as posições jurídicas que contempla se irradiam com extrema complexidade determinando direitos de abstenção e de prestação dos cidadãos em relação ao Estado, mas ainda um recíproco dever de proteção ambiental que se impõe para o Estado e para a coletividade por decorrência de um valor constitucional ambiental objetivado pela Constituição.

A par da diversidade de posições jurídicas que são possíveis de serem estabelecidas pelo direito fundamental ao meio ambiente, o princípio da vedação do retrocesso ambiental consiste em princípio constitucional dirigido ao Estado, uma vez que é este o detentor do poder de realização das atividades legislativas e administrativas que irão, ao final, implicar em alterações no conteúdo e nos procedimentos relativos ao meio ambiente. As políticas estatais, mesmo que não sejam diretamente destinadas a tratar de matéria ambiental, como as intervenções na ordem econômica, política e social, culminam, não raro, em alterações indiretas ao patrimônio jurídico ambiental, de modo que se faz necessário ao Estado prever tal encadeamento e zelar para que suas diretrizes e ações contemplem as alterações que possam provocar no meio ambiente. Desse modo, o princípio da proibição do retrocesso ambiental não se dirige aos indivíduos ou à coletividade porque não são eles detentores do poder de executar as políticas públicas ambientais, sejam elas legislativas, administrativas ou judiciárias, mas possuem, isto sim, o dever de cooperação com o Estado para que este possa determinar as políticas públicas ambientais de forma harmônica e adequada à preservação do patrimônio jurídico ambiental.

\footnotetext{
${ }^{444}$ REsp 302906/SP, de relatoria do Ministro Herman Benjamin, 2a Turma do Superior Tribunal de Justiça, publicado em 01.12.2010.
} 
Por se tratar de princípio vinculante e com aplicação imediata, a vedação do retrocesso autoriza que, em havendo significativa diminuição do grau de proteção ao direito fundamental ao meio ambiente motivada por medidas legislativas que pretendam priorizar outros direitos, seja possível a realização de um controle judicial sobre a constitucionalidade dessas legislações. O princípio da vedação do retrocesso ambiental se presta a servir de condutor da atuação estatal, de modo que esta se manifeste sob a observância de não redução do direito fundamental ao meio ambiente, sob pena de, em eliminando os direitos socioambientais mínimos relacionados com a dignidade da pessoa humana, se sujeitar a controle judicial de sua constitucionalidade. Sob outro ângulo, o princípio da vedação do retrocesso ambiental possui a eficácia de servir como parâmetro para a análise da constitucionalidade da medida questionada quando da adoção dos critérios da proporcionalidade pelo julgador.

\section{Conclusão}

O princípio da vedação do retrocesso encontra razão na caracterização do direito fundamental ao meio ambiente como um direito fundamental completo, dada a peculiaridade deste direito contemplar um complexo feixe de posições jusfundamentais que abarcam tanto o direito de se exigir do Estado posições prestacionais para aumentar a proteção do ambiente como posições negativas que impliquem em condutas de abstenção do Estado.

A vedação do retrocesso ambiental surge como um princípio constitucional implícito na Constituição brasileira, responsável por assegurar o núcleo essencial do direito fundamental ao meio ambiente ecologicamente equilibrado com esteio no prestígio à segurança jurídica, ao direito adquirido, ao ato jurídico perfeito, à coisa julgada e aos limites materiais à reforma constitucional.

O reconhecimento de limites à ação estatal no sentido de não intervir no patrimônio jurídico ambiental acrescentado pela humanidade, bem como de um dever de progressividade em relação aos avanços já conquistados constituem a dupla função do princípio da vedação do retrocesso. Tal princípio não se dirige aos cidadãos, mas com exclusividade ao Estado por possuir como tarefa primordial a execução de políticas legislativas, administrativas e judiciárias que se prestem a maximizar as garantias do direito fundamental ao ambiente enquanto projeção do princípio da dignidade da pessoa humana.

Por representar princípio constitucional com efeito vinculante e aplicação imediata a vedação do retrocesso ambiental autoriza que as medidas estatais que suprimam ou diminuam o nível de proteção do direito fundamental ao ambiente se submetam a controle judicial de sua constitucionalidade, possuindo, sobretudo, a função de servir ao julgador como filtro para a análise da constitucionalidade de tais medidas quando da aplicação dos critérios da proporcionalidade. 


\section{REFERÊNCIAS}

ALEXY, Robert. Teoria dos direitos fundamentais. Trad. Virgílio Afonso da Silva. São Paulo: Malheiros, 2008.

CANOTILHO, José Joaquim Gomes. O direito ao ambiente como direito subjectivo. In: Estudos sobre direitos fundamentais. Coimbra: Coimbra Editora. São Paulo: Revista dos Tribunais, 2008.

DECLARAÇÃO DA CONFERÊNCIA DAS NAÇÕES UNIDAS SOBRE MEIO AMBIENTE E DESENVOLVIMENTO. Rio de Janeiro: 3 a 14 de junho de 1992. Disponível em: http://www.defensoria.sp.gov.br/dpesp/ Repositorio/31/Documentos/Declara\%C3\%A7\%C3\%A3o\%20do\%20RJ\%20 sobre $\% 20$ meio $\% 20$ ambiente $\% 20$ e\%20desenvolvimento\%20-\%201992.pdf. Acessado em: 27.08.2012.

DECLARAÇÃO DA CONFERÊNCIA DAS NAÇÕES UNIDAS SOBRE MEIO AMBIENTE HUMANO. Estocolmo: 5 a 16 de junho de 1972. Disponível em: http:// www.onu.org.br/rio20/img/2012/01/estocolmo1972.pdf. Acessado em: 27.08.2012.

DERANI, Cristiane. Direito ambiental econômico. São Paulo: Max Limonad, 2001.

FENSTERSEIFER, Tiago. Direitos fundamentais e proteção do ambiente: a dimensão ecológica da dignidade humana no marco jurídico-constitucional do estado socioambiental de direito. Porto Alegre: Livraria do Advogado Editora, 2008.

FIORILlO, Celso Antonio Pacheco. O denominado "princípio" da vedação do retrocesso, suas atuais referencias no Supremo Tribunal Federal e eventuais aplicações no direito ambiental constitucional brasileiro. Disponível em: http://www.saraivajur.com.br/menuEsquerdo/doutrinaArtigosDetalhe. aspx?Doutrina=1167. Acessado em: 20.08.2012.

GAVIÃO FILHO, Anízio Pires. Direito fundamental ao ambiente. Porto Alegre: Livraria do Advogado Editora, 2005.

HESSE, Konrad. Elementos de direito constitucional da República Federativa da Alemanha. Tradução de Luís Afonso Heck. Porto Alegre: Fabris, 1998. In: GAVIÃO FILHO, Anízio Pires. Direito fundamental ao ambiente. Porto Alegre: Livraria do Advogado Editora, 2005. 
MOLINARO, Carlos Alberto. Direito ambiental. Proibição de retrocesso. Porto Alegre: Livraria do Advogado, 2007.

SARLET, Ingo Wolfgang; FENSTERSEIFER, Tiago. Direito constitucional ambiental. Estudos sobre a Constituição, os direitos fundamentais e a proteção do ambiente. Porto Alegre: Livraria do Advogado, 2011.

- A eficácia dos direitos fundamentais. Porto Alegre: Livraria do $\overline{\text { Advogado, }} 2005$.

. Direitos fundamentais sociais e proibição do retrocesso: algumas notas sobre o desafio da sobrevivência dos direitos sociais num contexto de crise. In: Revista do Instituto de Hermenêutica Jurídica, vol. 2. Porto Alegre: Instituto de Hermenêutica Jurídica, 2004.

- Direitos fundamentais sociais, 'mínimo existencial' e direito privado: breves notas sobre alguns aspectos da possível eficácia dos direitos sociais nas relações entre particulares. In: GALDINO, Flávio; SARMENTO, Daniel (Orgs.). Direitos fundamentais. Estudos em homenagem a Ricardo Lobo Torres. Rio de Janeiro: Renovar, 2006.

SILVA, Vasco Pereira da. Verde cor do direito. Lições de direito do ambiente. Coimbra: Almedina, 2003. 